\title{
Entre a liderança espiritual e a liderança servidora: a presença da espiritualidade nas ações de experientes CEOs
}

\section{Between spiritual leadership and servant leadership:the presence of spirituality in the actions of experienced CEOs}

\author{
VANDERLEI SOELA \\ ANTÔNIO MOREIRA DE CARVALHO NETO \\ DANIELA MARTINS DINIZ
}

\section{RESUMO}

Este artigo apresenta resultados de estudo destinado a investigar o lugar e a influência da espiritualidade no exercício da liderança. Para tanto, foi necessário conhecer as práticas de experientes executivos em posição de liderança e a presença da espiritualidade em suas ações, bem como investigar características do modo de liderança desses CEOs, verificando se estão presentes elementos da liderança servidora nas ações desses líderes. Para tanto, foram conduzidas entrevistas com doze executivos conhecidos publicamente no cenário brasileiro e/ou mundial, com notória trajetória em liderar organizações e pessoas de diferentes nacionalidades e culturas. Foi possível perceber nas falas dos CEOs entrevistados a presença dos principais fundamentos tanto da abordagem da liderança servidora, quanto da liderança espiritual. Foi possível notar também como eles consideram tais características fundamentais para o exercício de uma liderança mais efetiva. Os dados corroboram ainda a noção de que a espiritualidade é algo presente na vida e na prática dos CEOs entrevistados. Porém, na maioria das vezes, o tema é apresentado de forma inominada (sabe-se da presença de algo superior, mas não se sabe nomear); 
por vezes escondido (no silêncio da experiência de cada CEO); e até negligenciado (não se presta muita atenção a tais elementos, ainda que existam).

Palavras-Chave: Liderança Espiritual. Liderança Servidora. CEOs Sêniores.

\section{Abstract}

This article presents results of a study aimed at investigating the place and influence of spirituality in the exercise of leadership. For that, it was necessary to know the practices of experienced executives in a leadership position and the presence of spirituality in their actions, as well as investigate characteristics of the leadership mode of these CEOs, checking if there are elements of servant leadership in the actions of these leaders. To this end, interviews were conducted with twelve executives publicly known in the Brazilian and / or worldwide scenario, with a notorious trajectory in leading organizations and people of different nationalities and cultures. It was possible to perceive in the speeches of the CEOs interviewed the presence of the main fundamentals of both the approach of servant leadership and spiritual leadership. It was also possible to notice how they consider these characteristics fundamental to the exercise of more effective leadership. The data also corroborate the notion that spirituality is present in the life and practice of the CEOs interviewed. However, most of the time, the theme is presented in an unnamed way (it is known that something superior is present, but it is not known how to name it); sometimes hidden (in the silence of each CEO's experience); and even neglected (not much attention is paid to such elements, even if they exist). Keywords: Spiritual Leadership. Servant Leadership. Senior CEOs.

\section{INTRODUÇÃO}

Todo ser humano desenvolve a capacidade de ver e sentir o mundo à sua volta com as lentes que constrói em sua trajetória humana. A espiritualidade é uma experiência da subjetividade que consiste em um modo de estabelecer relação com o mundo em suas várias dimensões. 
A liderança, por sua vez, é um fenômeno relacional que brota do encontro entre subjetividades e, por isso, a força da liderança nasce na intersubjetividade (MALVEZZI, 2011). O exercício da liderança implica em lidar com essa peculiaridade da subjetividade humana, incluindo a dimensão espiritual. Mais do que uma dificuldade em dar conta de contemplar tal dimensão subjetiva, lidar com a espiritualidade reveste-se num desafio necessário na prática de liderar. A espiritualidade pode ser conceituada como um princípio vital que impulsiona o ser humano a fazer perguntas fundamentais sobre a origem, o fim da vida e as razões da existência humana. Ao mesmo tempo, é a intrínseca necessidade de ampliar contextos e significados, estabelecendo conexões, tanto em nível individual, como na comunidade humana e suas relações (SOLOMON, 2003).

As lideranças do século XXI são reconhecidas por sua capacidade de tomar decisões com agilidade e enfrentar ambientes de instabilidade. São cobradas, ao mesmo tempo, por elevados índices de produtividade e desempenho tanto pessoal como de suas equipes (SANT'ANNA; NELSON, 2014; OLIVEIRA et al., 2015; MENDES et al. 2020). Em tal ambiente de negócios, o que acontece com a 'alma' dos líderes? Essa questão, levantada por Benefiel (2008), demonstra que, com certa frequência, essa dimensão 'murcha' e 'morre', resultando em danos para o líder e para a organização que ele serve.

Nessa linha, diversos estudos evidenciam o impacto negativo que estas exigências têm causado na vida de executivos, como mostram a literatura (TANURE; CARVALHO NETO; ANDRADE, 2006; MOTA; TANURE; CARVALHO NETO, 2008; LOURENÇO; FERREIRA; BRITO, 2013; TANURE et al., 2015). A experiência cotidiana dos líderes nas organizações é marcada por grandes e constantes exigências que as organizações impõem sob pressão do mercado pelo alcance de resultados sempre mais ambiciosos, com necessidade de tomada de decisões rápidas. A busca de um equilíbrio entre vida pessoal e profissional fica muito comprometida. Por vezes, tais necessidades demandam um esforço quase sobre-humano. Ao mesmo tempo, Benefiel (2008) afirma que as Escolas de Negócios não são desenhadas para oferecer uma formação que contemple a espiritualidade. O que ocorre, em geral, é que tais instituições até 
mencionam a necessidade de tal investimento, porém, na prática, não incluem o tema no cerne de seus conteúdos.

Na dimensão teórica, a tentativa de trabalhar o tema 'espiritualidade' nos estudos organizacionais traz à tona certa confusão, pois é muito comum espiritualidade e religião serem tratadas como sinônimos. Mesmo que diversos autores já tenham apresentado a distinção entre ambas (indicando que religião se refere à dimensão externa, como instituições, dogmas e práticas e espiritualidade, por outro lado, se refere à vida interior, à dimensão subjetiva, experiencial e emocional), ainda há muita confusão na discussão de tais temáticas (SOLOMON, 2003; MOLTMANN, 2010; NULLENS, 2019; TENFEN; VENELLI-COSTA; VIEIRA; SANEMATSU, 2019).

Portanto, associar espiritualidade e liderança se torna um grande desafio. Ambos os construtos são polissêmicos, complexos e compartilham da falta de um consenso em relação às suas definições (DENT et al., 2005). De qualquer maneira, a busca por uma fundamentação teórica tem surgido no cenário acadêmico e alguns autores apontam um vasto caminho a percorrer, dado que espiritualidade relacionada à liderança ainda é uma dimensão bastante negligenciada, abrindo caminho para novos estudos sobre o lugar da espiritualidade na ação da liderança (AVOLIO et al., 2009; MACKENZIE; SERVANT, 2011; KARAKAS, 2010; DAY et al., 2013; GRÀCIA, 2014; KRISHNAKUMAR et al., 2015; KOK; HEUVEL, 2019).

Kok e Heuvel (2019), por exemplo, destacam a importância da liderança, do discernimento e da espiritualidade em tempos de volatilidade e incertezas. Ademais, nem sempre o tema aparece entre líderes empresariais pelo menos explicitamente. Em pesquisa realizada por Sant'Anna et al. (2012), sobre o que pensam os executivos brasileiros a respeito de liderança, é possível notar a ausência do tema "espiritualidade" entre os principais desafios mencionados na pesquisa.

Em pesquisa realizada na plataforma Scientific Periodicals Electronic Library (SPELL) da Associação Nacional de Pós-graduação e Pesquisa em Administração (ANPAD), em dezembro de 2020, o termo "espiritualidade" aparece em dezessete artigos, quase todos relacionados ao ambiente de trabalho. Com o termo "liderança espiritual", apenas uma citação foi encontrada na mesma base de 
dados (MARTINS; PEREIRA, 2009). Parece ser, portanto, uma indicação de que o tema se constitui em um campo fértil em termos de pesquisa e contribuição.

Tomando como referência o contexto apresentado, este estudo parte do princípio de que a espiritualidade tem importante papel no exercício da liderança, influenciando ações, escolhas e relacionamentos. A proposta central é, então, investigar o lugar e a influência da espiritualidade no exercício da liderança. Para tanto, foi necessário: i) conhecer as práticas de experientes executivos em posição de liderança e a presença da espiritualidade em suas ações; ii) investigar características do modo de liderança dos executivos entrevistados, verificando se estão presentes elementos da liderança servidora nas ações desses líderes. Para tanto, foram conduzidas entrevistas semiestruturadas com doze executivos conhecidos publicamente no cenário brasileiro e/ou mundial, com notória trajetória em liderar organizações e pessoas de diferentes nacionalidades e culturas.

Quanto à relevância da pesquisa, entende-se que conectar os temas espiritualidade e liderança possui importância acadêmica, dado a necessidade de aprofundamento no tema, e relevância empírica pelos seguintes motivos (embora não esgotem o assunto): i) estreitar a distância existente entre o universo da gestão e do ambiente de negócios e a noção de espiritualidade; ii) fornecer insights que contribuem, de alguma forma, para a formação de lideranças mais 'espirituais' capazes de lidar com a complexidade e volatilidade do contexto empresarial; iii) promover maior abertura para a vivência e partilha do tema da espiritualidade nos diversos ambientes de negócios.

\section{REFERENCIAL TEÓRICO}

\subsection{Espiritualidade e Liderança}

Estudos apontam que há vários desafios quando se busca entender a espiritualidade relacionada à liderança. Dentre outros, está a tentativa de compreender a espiritualidade diferenciada de religião, credo ou práticas religiosas (FRY, 2003; SOLOMON, 2003; REAVE, 2005; GEHRKE, 2008; AVOLIO et al., 2009; KARAKAS, 2010; KRISHNAKUMAR et al., 2015; HOLLOWAY, 2015; NULLENS, 
2019; DAMIÃO, OSWALDO; VIEIRA, 2020). Com frequência, espiritualidade é associada exclusivamente à religião, esvaziando ou limitando a abrangência do termo. Bolman e Deal (1996) apontam que "espiritualidade é meta; religião é caminho" (p. 20). Nessa direção, este estudo leva em conta a espiritualidade na perspectiva da busca de sentido, como elemento fundante e integrador das ações da liderança (MESKELIS et al., 2016).

Na literatura especializada sobre liderança espiritual, um dos trabalhos que mais se destacam é o de Louis W. Fry (2003), um dos autores-referência no horizonte de reflexão sobre a espiritualidade relacionada à liderança. O autor define "liderança espiritual" como uma combinação de valores, atitudes e comportamentos necessários para motivar a si e aos demais, construindo um senso de sobrevivência como chamado (intrinsicamente motivador) e filiação (adesão ou pertencimento).

Para Fry (2003), liderança espiritual baseia-se em um modelo de motivação intrínseca que incorpora visão, esperança/fé e amor altruísta. O propósito da liderança espiritual seria criar congruência de visão e valor no indivíduo e nas equipes e, em última instância, promover níveis mais elevados de comprometimento e produtividade. Nessa direção, liderança espiritual “envolve motivar e inspirar os trabalhadores através de uma visão transcendente e uma cultura corporativa baseada em valores altruístas a fim de produzir uma força de trabalho motivada, comprometida e produtiva" (FRY; SLOCUM JR., 2007, p. 90). O autor destaca, ainda, que o atual contexto de negócios demanda “(...) uma visão mais holística de liderança que integre as quatro arenas fundamentais que definem a existência humana: o corpo, a mente, o coração e o espírito" (FRY; SLOCUM JR., 2007, p. 694).

A liderança espiritual, na concepção de Fry (2003) e Fry e Slocum, (2007) implica em dois movimentos centrais: i) criar uma visão em que os membros da organização - líderes e seguidores experimentem um senso de convocação (chamado) de maneira que suas vidas nas organizações tenham sentido e façam diferença; iii) estabelecer um cultura social/organizacional baseada em valores de amor altruísta através dos quais líderes e seguidores se sintam compreendidos e admirados e tenham preocupação /apreço por si 
mesmos e pelos outros. O modelo de liderança espiritual abaixo contempla os elementos ora discutidos.

\section{Figura 1 - Modelo causal da Liderança Espiritual}

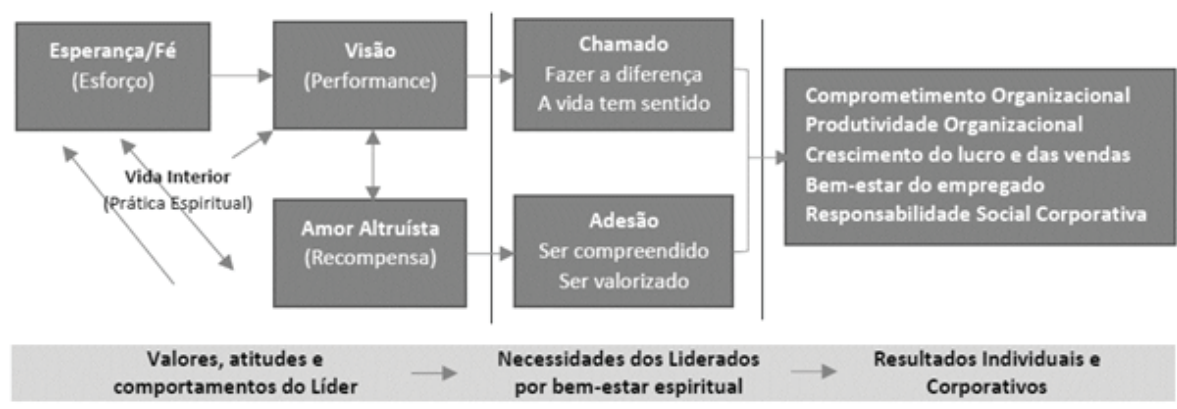

Fonte: Baseado em Fry (2003); Fry e Slocum (2007); Fry e Altman (2013).

O tripé Esperança/Fé, Visão e Amor Altruísta fundamenta a noção de liderança espiritual e é a combinação desses três aspectos que influencia positivamente os indivíduos na organização. Essa influência visa aumentar a motivação intrínseca dos indivíduos para que considerem o trabalho mais como chamado (convocação) do que como recompensa externa (KRISHNAKUMAR et al., 2015), podendo levar, consequentemente, a um maior comprometimento e produtividade organizacionais. Por essa razão é chamado de "modelo causal".

A visão, de acordo com o texto original de Fry (2003), diz respeito à capacidade de enxergar onde se deseja que a organização esteja num futuro próximo. Visão ajuda a clarear a direção, simplificar as decisões e coordenar as ações das pessoas com mais eficiência. $\mathrm{O}$ amor altruísta, por sua vez, é definido como sentido de harmonia e bem-estar, resultado de cuidado, preocupação e apreço por si e pelos outros. Acompanham essa definição a noção de paciência, bondade, humildade, altruísmo, confiança e lealdade. Por fim, esperança/fé são colocados como dois elementos conjugados. Segundo Fry (2003), fé é a convicção que uma coisa não provada por evidência física seja verdade e esperança é o desejo com a expectativa de realização. No mundo das organizações, esperança/fé é fonte de convicção que sua visão e missão podem ser realizados. 
Na raiz da conexão entre espiritualidade e liderança está esta experiência da vida interior, ou seja, o reconhecimento de que os indivíduos possuem uma voz interior que é fonte de sabedoria nas decisões profissionais e pessoais, como narra Levy (2000), após um curso de espiritualidade para executivos: “(...) nos casos de decisões difíceis, há informações insuficientes, muita incerteza e inúmeras possibilidades". A resposta não é encontrada do lado de fora, mas dentro de nós (LEVY, 2000, p. 130).

Na vida interior está a experiência da transcendência, ou seja, ir além dos próprios interesses e conectar com algo superior maior do que a si mesmo. De acordo com Fry e Altman (2013), além de ser um importante caminho para auxiliar o líder a ir além de seus próprios interesses, a experiência da transcendência permite conectar-se com algo maior e, por conseguinte, criar propósito e sentido para si e para os demais, mudando a percepção de si, do que realizam, do mundo a sua volta e de seus comportamentos.

\subsection{Liderança Servidora}

Apesar de a liderança despontar como elemento crucial diante dos desafios vividos pela sociedade e pelas organizações em geral (FERNANDES; SIQUEIRA; VIEIRA, 2014; GANDOLFI; STONE, 2017), as mudanças substanciais do século XXI revelam que muitos modelos populares de liderança se mostram insuficientes para lidar com a complexidade deste tempo (MALVEZZI, 2011; DUMAS; BEINECKE, 2018).

Considerando que este estudo tem como cerne a noção de espiritualidade, a abordagem da liderança servidora surge como importante fonte para compreensão e vivência do tema. Tal perspectiva foi introduzida em 1977 por Robert K. Greenleaf, que pontua que o líder servidor é aquele que primeiro escolhe servir e, como consequência, surge uma aspiração de liderar os outros (GREENLEAF, 2002).

A liderança servidora tem ganhado crescente interesse dentro e fora da academia (LIDEN et al., 2015; VAN DIERENDONCK; PATTERSON, 2015; HEYLER; MARTIN, 2018). Autores como Heyler e Martin (2018) apresentam diversos estudos empíricos evidenciando como a liderança servidora tem trazido benefícios em diferentes contextos, como na gestão de enfermagem, no aprendizado organiza- 
cional e na diminuição de turnover. Mencionam, ainda, que empresas ranqueadas entre as melhores para se trabalhar da Revista Fortune de 2017 adotaram os princípios da liderança servidora.

A liderança servidora tem sido descrita como um chamado altruísta devido ao "desejo profundamente enraizado de um líder de fazer uma diferença positiva na vida dos outros" (BARBUTO; WHEELER, 2006, p. 318). Heyler e Martin (2018) e chamam atenção para o fato de que a teoria da liderança servidora "inverte a pirâmide" da organização, de tal forma que os líderes servem aos demais membros da organização.

Patterson (2003) aponta que o líder servidor tem como foco os seguidores, adaptando o seu comportamento e ação ao perfil e necessidade dos liderados. $\mathrm{O}$ autor aponta ainda que a liderança servidora se baseia em sete construtos: amor, humildade, altruísmo, visão, confiança, empoderamento e serviço, sendo alguns elementos constantes no modelo de Fry (2003). A confiança aparece como a pedra-angular da liderança servidora. O serviço, por sua vez, brota da experiência do amor.

A liderança servidora é diferente de outras teorias de liderança, como, por exemplo, a liderança transformacional. A liderança servidora "concentra-se no desejo de servir e preparar os outros para servir também, enquanto a liderança transformacional enfatiza o desejo de liderar e inspirar seguidores para um bom desempenho" (VAN DIERENDONCK et al., 2014, p. 546). O autor resume as principais características dos líderes servidores em seis elementos: capacitam e desenvolvem pessoas; demonstram humildade; são autênticos; aceitam as pessoas pelo que elas são; promovem direcionamento; e se colocam a serviço para o bem do todo.

No núcleo da relação entre o líder-servidor e o liderado está a intrínseca crença por parte do líder no valor intrínseco de cada indivíduo (VAN DIERENDONCK, 2011). Por isso, reconhecimento, apreciação e validação das habilidades de cada indivíduo é uma das marcas da liderança servidora. Pelo fato de ser um estilo de liderança centrado na pessoa, é possível notar três aspectos importantes que geralmente são percebidos nos empregados: crescimento pessoal, atitudes positivas no trabalho e desempenho da equipe (VAN DIERENDONCK, 2011). 
Marques (2018) apresenta uma comparação entre uma liderança baseada em comando/controle e uma liderança servidora:

Quadro 1 - Comparativo entre modelos de liderança

\begin{tabular}{|l|l|l|}
\hline & \multicolumn{1}{|c|}{ Comando e Controle } & \multicolumn{1}{c|}{ Liderança Servidora } \\
\hline Metáfora & A organização é uma máquina. & $\begin{array}{l}\text { Estrutura orgânica de relações inter- } \\
\text { pessoais. }\end{array}$ \\
\hline Autoridade & De cima para baixo. & Participação de todo o grupo. \\
\hline Pessoas & Instrumentos de produção. & $\begin{array}{l}\text { Os ativos principais e grande fonte de } \\
\text { criatividade. }\end{array}$ \\
\hline Estilo de liderança & Distante e desligado. & Ligado e presente. \\
\hline Supervisão & Dita, controla e pune. & Ouve, facilita, encoraja. \\
\hline Metáfora & $\begin{array}{l}\text { Autosserviço: o que podes fazer por } \\
\text { mim e pela organização? }\end{array}$ & $\begin{array}{l}\text { Hétero-serviço: o que posso fazer para te } \\
\text { ajudar a cumprir a sua missão? }\end{array}$ \\
\hline
\end{tabular}

Fonte: Marques (2018).

Com base no exposto, é possível observar que a liderança servidora tem relação direta com a noção de uma espiritualidade da liderança. Isto porque, seus principais atributos carregam elementos da espiritualidade, como, humildade, empoderamento, desenvolvimento do outro, etc. A dimensão de serviço, especialmente, vai ao encontro de importantes aspectos da espiritualidade, como confiança, transcendência e relacionamento baseado no respeito.

\section{Metodologia da Pesquisa}

Dado o propósito desse estudo de associar as complexas temáticas de espiritualidade e liderança, optou-se pela realização de pesquisa qualitativa, baseada no método de estudo de caso, junto a executivos experientes que atuam em diferentes setores econômicos. A partir de entrevistas semiestruturadas foi possível dar voz aos executivos entrevistados, bem como captar em profundidade suas crenças, experiências e comportamentos ao longo de sua larga vivência como CEOs, levando em consideração a complexidade do tema espiritualidade no ambiente de negócios. A pesquisa qualitativa tem interesse, justamente, em compreender o significado que as pessoas dão ao mundo ao seu redor, tal qual se constata pelos 
argumentos de Yin (1981), de Eisenhardt e Graebner (2007) e de Vieira e Rivera (2012).

Quanto ao instrumento de coleta de dados, foram conduzidas entrevistas semiestruturadas com doze líderes/executivos conhecidos publicamente no cenário brasileiro e/ou mundial, com notória trajetória em liderar organizações e pessoas de diferentes nacionalidades e culturas. Foram selecionados, portanto, homens e mulheres que estão à frente dos negócios em nível estratégico de grandes organizações atuando no Brasil e no mundo há tempo significativo (na maior arte das trajetórias atuaram e atuam como presidentes e, em menor tempo como diretores). A média de tempo como CEO dos executivos entrevistados foi de 31 anos, conforme caracterização constante no Quadro 2.

\section{Quadro 2 - Perfil dos entrevistados}

\begin{tabular}{|c|c|c|c|c|c|c|}
\hline Empresas & CE0 & Sexo & Idade & $\begin{array}{c}\text { Setor de atuação da } \\
\text { empresa que dirige } \\
\text { atualmente }\end{array}$ & $\begin{array}{c}\text { Número de } \\
\text { funcionários } \\
\text { da empresa }\end{array}$ & $\begin{array}{c}\text { Tempo como } \\
\text { Diretores e } \\
\text { CEOs }\end{array}$ \\
\hline E1 & 1 & M & 64 & Financeiro & 50.000 & 40 anos \\
\hline E2 & 2 & M & 65 & $\begin{array}{c}\text { Tecnológica e } \\
\text { sustentabilidade }\end{array}$ & 1.000 & 30 anos \\
\hline E3 & 3 & M & 68 & $\begin{array}{c}\text { Arquitetura e } \\
\text { Urbanismo }\end{array}$ & 30 & 44 anos \\
\hline E4 & 4 & M & 62 & Construção Civil & 24.000 & 40 anos \\
\hline E5 & 5 & M & & Saúde & 30 anos \\
\hline E6 & 6 & M & 77 & Educação & 500 & 42 anos \\
\hline E7 & 7 & M & 59 & $\begin{array}{c}\text { Tecnologia Diversi- } \\
\text { ficada }\end{array}$ & 90.000 & 36 anos \\
\hline E8 & 8 & M & 87 & $\begin{array}{c}\text { Engenharia Aero- } \\
\text { náutica e Educação }\end{array}$ & 95.000 & 22 anos \\
\hline E9 & 9 & M & 66 & Beleza & 8.000 & 20 anos \\
\hline E10 & 10 & F & 64 & Saúde & 4.500 & 33 anos \\
\hline E11 & 11 & F & 68 & Department Store & 24.000 & 27 anos \\
\hline E12 & 12 & F & 62 & Moda & 2.600 & 13 anos \\
\hline
\end{tabular}

Fonte: Dados da pesquisa. 
Os critérios de escolha dos entrevistados foram: i) senioridade e trajetória de, no mínimo, 10 anos como CEO; ii) elevado reconhecimento público em ambientes empresariais e de negócios, ou seja, executivos que fizeram história em suas organizações e na sociedade em geral. $\mathrm{O}$ acesso a esses profissionais foi possível devido à rede qualificada estabelecida com tais contatos e de informações colhidas na Fundação Dom Cabral (FDC), escola de negócios brasileira fundada desde 1976 e de renome internacional.

Vale salientar que os executivos entrevistados são figuras muito reconhecidas, referências no mundo dos negócios, como o fundador de uma das maiores empresas de cosméticos do Brasil; uma empresária que comandou uma das maiores redes varejistas do Brasil; um dos proprietários da empresa líder da América Latina na área de construção civil; um ex-presidente de Banco multinacional, dentre outras figuras relevantes no mundo corporativo nacional e internacional.

As dez questões constantes no roteiro de entrevista (anexo) foram elaboradas tomando como referência expressões que remetem à noção de espiritualidade, tais como: crise, tomada de decisão, busca de sentido, integração vida pessoal e profissional, celebração das conquistas, fontes de inspiração. Tal roteiro foi inicialmente aplicado em um dos executivos participantes da pesquisa como entrevista-piloto.

A coleta de dados foi feita em espaço reservado dentro das empresas em que trabalham os executivos e cada entrevista teve duração média 60 minutos, sendo posteriormente transcritas para facilitar o tratamento qualitativo. Para tanto, foi adotada a técnica de análise de conteúdo "categorial" ou semântica, que consiste em examinar, categorizar, classificar e recombinar as evidências empíricas (SILVA; FOSSÁ, 2013; BARDIN, 2016). É denominada de "categorial", pois implica em desmembrar o texto em unidades/ categorias segundo reagrupamentos analógicos com o intuito de facilitar a organização e a interpretação dos dados qualitativos.

Os passos adotados na análise de conteúdo seguiram a lógica proposta por Silva e Fossá (2013), qual seja: 1) Leitura geral do material coletado; 2) Codificação para formulação de categorias de análise, utilizando a teoria e as indicações trazidas pela leitura geral; 3) Recorte e organização do material em unidades de registro (palavras, frases) comparáveis e com o mesmo conteúdo semântico; 
4) Estabelecimento de categorias que se diferenciam, tematicamente nas unidades de registro (passagem de dados brutos para dados organizados). A formulação dessas categorias segue os princípios da exclusão mútua (entre categorias), da homogeneidade (dentro das categorias), da pertinência na mensagem transmitida (não distorção), da fertilidade (para as inferências) e da objetividade (compreensão e clareza); 5) agrupamento das unidades de registro em categorias comuns; 6) agrupamento progressivo das categorias (iniciais ๑) intermediárias @ finais); 7) inferência e interpretação respaldadas no referencial teórico.

Portanto, após leitura do material transcrito, foi elaborada uma tabela com os principais temas emergentes do campo empírico. Em seguida, foi possível confrontar os relatos dos entrevistados com as abordagens de Fry (2003) e da liderança servidora. Na sequência, os dados categorizados foram tratados e inferências foram feitas, reunidas na próxima seção deste artigo.

\section{DESCRIÇÃo E ANÁLISE DOS DADOS}

\subsection{Espiritualidade: dimensão escondida, mas presente no discurso dos CEOs}

A questão que norteou a investigação aqui apresentada foi "qual é o lugar e a influência da espiritualidade na ação da liderança?”. As entrevistas com CEOs revelam algo inusitado: a espiritualidade parece ser uma realidade escondida, negligenciada e até mesmo negada, mas seus fundamentos estão presentes nas falas dos entrevistados. Uma inferência é que o tema pode ser muitas vezes compreendido como algo necessariamente vinculado à noção de religiosidade e de práticas religiosas, limitando uma compreensão mais ampla do assunto (SOLOMON, 2003; MOLTMANN, 2010; NULLENS, 2019). Em alguns casos, é possível perceber que tratar de espiritualidade até surpreende os entrevistados:

Você perguntou da espiritualidade. É a primeira vez que alguém me pergunta disso; na minha vida inteira ninguém me perguntou isso... preciso pensar para responder. Eu sei que me faz bem. Eu sinto, de fato que tem uma chama aqui dentro e essa chama (...) é a voz interior, né? (CEO 1). 
Já o CEO 5 demonstra certa dificuldade em lidar com o tema no meio em que atua e com quem convive. Daí espiritualidade, mesmo que vivenciada de alguma maneira, parece algo que deve ficar escondido:

Isso é um assunto delicado, porque pode parecer que a gente que trabalha com ciências, rejeitamos a ideia de uma imagem mística (...). É difícil a gente expressar esse lado interior para um grupo que está farto de ferramentas técnicas (CEO 5).

Ao serem abordados se são "pessoas de fé" com muita frequência se constata uma distinção clara entre "ter fé" e "ter religião ou práticas religiosas". Embora alguns tenham vivido uma experiência ligada a certas práticas (missa, igreja, orações, etc.), fazem questão de afirmar que são pessoas de fé, porém não religiosas. É o caso, por exemplo, dos CEOs 4, 5, 6, 7, 9 e 11: “Tenho muita fé, uma fé assumida. Eu não tenho religião, mas eu tenho fé" (CEO 11). No caso do CEO 9, a máxima se repete, quando afirma "não sou religioso, mas sou uma pessoa de fé". E completa: "Fé no sentido de respeitar algo superior". Mesmo em alguns casos, quando o entrevistado diz ser uma pessoa de fé e mesmo religiosa, nota-se que o imaginário religioso construído em experiências anteriores ainda joga importante papel, tanto na compreensão do tema quanto na sua prática cotidiana e na sua forma de exercer liderança.

Tais achados reforçam o que alguns autores discutem ao tentar decifrar essa diferença entre espiritualidade e religião (FRY, 2003; SOLOMON, 2003; REAVE, 2005; GEHRKE, 2008; AVOLIO et al., 2009; KARAKAS, 2010; KRISHNAKUMAR et al., 2015; HOLLOWAY, 2015; NULLENS, 2019). Os CEOs corroboram com o que tais autores assinalam, especialmente Nullens (2019): religião refere-se à dimensão externa e espiritualidade, por outro lado, refere-se à vida interior, à dimensão subjetiva e emocional.

Outro aspecto que os dados apontam é a confirmação de que há, sim, uma espiritualidade subjacente à prática dos líderes entrevistados, embora seja muitas vezes escondida, negada ou até negligenciada, seja pelo desconhecimento, seja pela ausência uma visão mais abrangente do tema ou ainda pela dificuldade que encontram 
em compartilhar suas experiências mais subjetivas. Por outro lado, há algo que "anima" essas pessoas no cotidiano exercício de liderar e uma "busca interna" para a resolução de problemas que enfrentam nas organizações. Tais executivos parecem não ter clareza dessa "força interior que impulsiona" desde o princípio de suas jornadas (FRY; SLOCUM JR., 2007), mas, vão se dando conta de que há um sentido interno no que realizam e confirmam isso ao percorrerem o caminho.

Na grande maioria das entrevistas é possível reconhecer que estes executivos carregam importantes elementos que revelam a presença e a ação da espiritualidade no exercício da liderança. Algumas expressões emergentes nos dados que apontam para a noção de liderança espiritual com base nos pilares do modelo de Fry (2003) são reunidas no Quadro 3.

\section{Quadro 3 - Elementos da Liderança Espiritual}

\begin{tabular}{|c|c|c|}
\hline Fé & Amor & Visão \\
\hline $\begin{array}{l}\text { Líder que crê; } \\
\text {. No mundo interno, pessoal; } \\
\text { Fé = propósito; } \\
\text {. Fé na vida e nas pessoas; } \\
\text { Fé ajuda a pavimentar o } \\
\text { caminho } \\
\text {. Chama interior } \\
\text { Realizar algo superior }\end{array}$ & $\begin{array}{l}\text {. Lidar com o intangível } \\
\text { Escutar o outro } \\
\text {. Olhar o mundo de um jeito } \\
\text { diferente } \\
\text {. Dar sentido } \\
\text {. Abertura e confiança } \\
\text {. Fazer o bem }\end{array}$ & $\begin{array}{l}\text { Agir no presente de olho no } \\
\text { futuro } \\
\text {. Fazer perguntas } \\
\text {. Intuição } \\
\text { Olhos no horizonte, cabeça } \\
\text { nas estrelas } \\
\text {. Em qualquer situação compli- } \\
\text { cada, eu acho oportunidades }\end{array}$ \\
\hline $\begin{array}{l}\text { "A fé é o combustível maior e } \\
\text { mais importante, sem a menor } \\
\text { dúvida. E a gente não vê como } \\
\text { ser bem-sucedido sem ter esse } \\
\text { ingrediente da fé". (CEO 2) }\end{array}$ & $\begin{array}{l}\text { "Eu já comecei a falar na em- } \\
\text { presa em amor. Uma loucura, } \\
\text { ninguém fala. E daí eu falei a } \\
\text { um monte de banqueiros, de } \\
\text { coração, de amor. Pô, mas você } \\
\text { fala dessas coisas? Os caras não } \\
\text { falam." (CEO 1). }\end{array}$ & $\begin{array}{l}\text { "Nós não temos a capacidade } \\
\text { de adivinhar o futuro. Mas } \\
\text { temos condições de colocar } \\
\text { algumas pontes que podem } \\
\text { tornar o futuro uma realidade. } \\
\text { O que é preciso é acreditar } \\
\text { naqueles pontos que podem } \\
\text { servir de sustentáculo para um } \\
\text { salto para o futuro." (CEO 8). }\end{array}$ \\
\hline
\end{tabular}

Fonte: Elaborado pelos autores com base nos dados.

Vale ressaltar, entretanto, que a noção de amor não é apresentada de forma direta pela grande maioria dos entrevistados, mas sim de forma subjacente nos relatos, seja quando abordam a noção de ações baseadas na moral, seja quando falam do cuidado e pre- 
ocupação com as pessoas (CEO 1, 6, 9, 10): Então é isso, eu posso ajudar as pessoas e posso ajudar esse mundo a ser um mundo um pouco melhor (CEO 1). Aliás o cuidado com o ser humano foi um aspecto recorrentemente citado nas entrevistas, corroborando a noção de que liderar implica em lidar com essa peculiaridade da subjetividade humana.

\subsection{Noções de Liderança Servidora emergem das falas dos CEOS}

Nas entrevistas com os CEOs, nota-se que o fenômeno da liderança é caracterizado pelos executivos com atributos relacionados à noção de liderança servidora. Isso é perceptível na forma como entendem e praticam a liderança, conforme expressões recorrentemente citadas nas entrevistas: coletividade, cuidado, confiança, influência, ser e dar exemplo, respeito ao ser humano (BARBUTO; WHEELER, 2006; VAN DIERENDONCK, 2011; VAN DIERENDONCK et al., 2014; MARQUES, 2018). Ademais, em nenhum momento os entrevistados demonstram qualquer sinal de que já nasceram para isso. Pelo contrário, revelam que foram desenvolvendo algumas características de liderança na prática, em meio aos desafios cotidianos e no confronto de ideias com as pessoas.

Há evidências claras de que os executivos só chegaram onde chegaram porque tiveram a sensibilidade com o lado humano (MALVEZZI, 2011), de reconhecer qualidades e defeitos em si e nos demais; foram capazes de valorizar a contribuição de cada indivíduo e das equipes; souberam criar condições para as pessoas se desenvolverem. A maioria dos entrevistados relata, ainda, que uma liderança efetiva depende, em grande parte, da sensibilidade com pessoas e dos relacionamentos que estabelecem com elas, conforme relatos abaixo. Portanto, a dimensão relacional, além da humana, também foi bastante destacada pelos executivos:

Você tem que tratar as pessoas como se fosse um jardim e desenvolver pessoas é um ato humano, é um ato de amor (CEO 12).

Comecei a ver que a gestão de pessoas, a liderança de pessoas tem muito mais a ver com você entender a dinâmica de cada indivíduo 
ou de uma sociedade do que tentar métodos cartesianos e acabei enveredando muito por esse caminho, sem deixar de ter o meu lado matemático, mas tratar as pessoas e entender as pessoas, respeitar as pessoas, seja cliente, funcionário, chefe, concorrente e acho que fez uma grande diferença isso (CEO 1).

Segundo o mesmo CEO, a noção de liderança tem mudado significativamente ao longo dos anos, dado que o modelo "comand and control" já não se adequa mais em inúmeras situações e contextos na atualidade (MALVEZZI, 2011; DUMAS; BEINECKE, 2018). Como Greenleaf (2002) aponta, a liderança servidora está mais relacionada com a noção de suporte e engajamento individual/coletivo do que de coerção e controle. O CEO1 complementa, ainda, que: "o meu estilo nunca foi esse, foi sempre de engajamento e acho que teve me conectado com esse sentimento de que a gente precisa ter mais transparência, mais ética, mais responsabilidade no trato da coisa comum?" (CEO 1).

Portanto, ao invés de supervisionar e controlar pessoas como se a liderança fosse uma tarefa unilateral, os executivos entrevistados realizam uma gestão baseada no empoderamento (PATTERSON, 2003) e na valorização da coletividade e do trabalho em equipe (FRY, 2003; VAN DIERENDONCK, 2011; VAN DIERENDONCK et al., 2014), aspectos citados como relevantes em praticamente todas as entrevistas. Na visão do CEO 8, por exemplo, o mais importante não é figura do líder em si, mas a sua capacidade de valorizar a equipe e criar paixão nas pessoas:

Eu sempre dizia pra mim próprio, eu não sou um cara importante. O que era importante era o que tinha na cabeça, espírito de equipe, espírito de corpo e de criar paixão. Criar paixão pelo que estava fazendo, colocando os objetivos da empresa na cabeça dos $18 \mathrm{mil}$ empregados (CEO 8).

Nessa mesma linha, o CEO 11 revela: “Eu trabalho muito em grupo; eu faço muito mais perguntas inteligentes; eu descentralizo muito eu empodero muito fácil as pessoas". 
Os dados revelam que o líder tem esse papel de estimular e direcionar gerando comprometimento nos indivíduos para a causa (FRY; ALTMAN, 2013), seja ela proposta pela liderança ou gerada coletivamente. Nesse sentido, os indivíduos aderem ao propósito não em razão de uma hierarquia ou posição formal, mas de forma espontânea, por respeito e confiança no líder. Eles passam a considerar o trabalho como um chamado (FRY, 2003; KRISHNAKUMAR et al., 2015). A perspectiva da liderança servidora baseia-se justamente na noção de que os indivíduos responderão livremente somente àqueles que são escolhidos como líderes porque são confiáveis e servidores e não por algo imposto de "cima para baixo" (GREENLEAF, 2002; MARQUES, 2018). Os relatos abaixo tangenciam tal discussão:

Minha satisfação é poder gerar essa expectativa nas pessoas para uma mudança e algo diferente, olhar e achar a melhoria, fazer algo superior (CEO 7).

Todo mundo entrava na minha sala a hora que queria, desde o funcionário mais simples até o engenheiro mais sofisticado. E papeava com eles, andava pela fábrica, andava pelos escritórios técnicos, sentava com eles, resolvia problemas com eles, dava a nova direção, mas na base de confiança e eles confiavam em mim e eu confiava neles. (CEO 8).

Nessa direção, a noção de confiança foi uma característica mencionada no relato de todos os executivos entrevistados. Para o CEO 8, por exemplo, "confiança é base da liderança".

As categorias "confiança" e "empoderamento", particularmente, são muito presentes na teoria da liderança servidora. Patterson (2003), por exemplo reforça que a confiança constitui pedra-angular da teoria e o serviço brota da experiência do amor. O empoderamento, por sua vez, acontece pelas ações de capacitação e desenvolvimento das pessoas, um dos pilares da liderança servidora.

Os dados apontam, também, que a consideração com o outro é conditio sine qua non de uma boa liderança, gerando, consequentemente, maior engajamento das pessoas aos propósitos do líder ou da organização (ou ao chamado, conforme sugere Fry, 2003). Os relatos abaixo ilustram tal discussão:

Isso exige muita paciência, muito desprendimento, saber lidar com diferentes personalidades. Exige, às vezes, você achar que aquela so- 
lução não é a melhor, mas foi a solução que aquele grupo ou aquela pessoa encontrou (CEO 6).

É nos momentos que você sente adesão do grupo (...). Não necessariamente a sua ideia, mas a ideia que surgiu e você vê o entusiasmo das pessoas na defesa daquela causa (CEO 9).

Nesse sentido, a liderança servidora também oferece importantes elementos para o exercício da liderança: se colocam a serviço para o bem coletivo; reconhecem e escutam o outro; valorizam habilidades individuais e coletivas (VAN DIERENDONCK, 2011). Isso requer um senso de humildade, característica discutida nos estudos de Fry (2003) e Patterson (2003), e mencionada por alguns executivos, dentre eles o CEO 9: "O exercício da liderança é delicado. Você precisa estar sempre atento, essa dose de humildade, de ouvir o outro". Conforme pontuam Heyler e Martin (2018), a teoria da liderança servidora "inverte a pirâmide" da organização de tal forma que os líderes servem aos demais membros da organização.

Por fim, a figura que segue reúne algumas das características do modo de liderança dos executivos entrevistados que corroboram a noção de liderança servidora.

Figura 2 - Elementos da Liderança Servidora

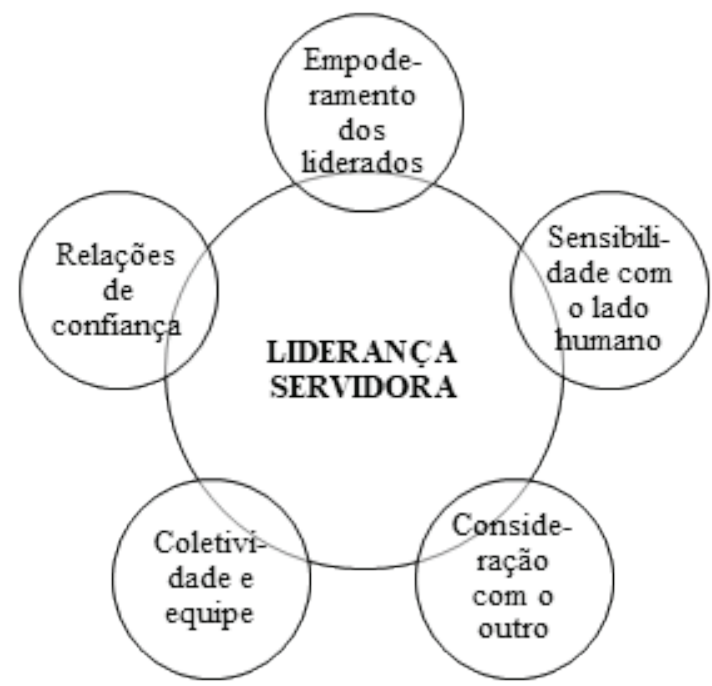

Fonte: elaborado pelos autores com base nos dados. 
Dado essa discussão, foi possível perceber nas falas dos CEOs entrevistados a presença dos principais fundamentos tanto da abordagem da liderança servidora (ver figura 2), como da liderança espiritual (ver Quadro 3). Ademais, foi possível notar como eles consideram tais características e atributos fundamentais para o exercício de uma liderança mais efetiva.

\section{CONSIDERAÇõeS FINAIS}

Os achados empíricos revelam, primeiramente, certa dificuldade, por parte de alguns entrevistados, na abordagem de temas mais de cunho existencial, religioso ou espiritual. Com certa facilidade, alguns destes executivos (com décadas de experiências de sucesso à frente de grandes empresas no Brasil e no mundo), desviam-se para temas adjacentes como forma de responder a certas questões. Especialmente quando se tocou em algo do mundo da interioridade, houve alguma incerteza ou confusão. Enquanto alguns CEOs foram mais explícitos quanto aos temas, outros permaneceram numa esfera mais racional, dando pouco espaço para aprofundar o assunto. Isso não deixa, de qualquer maneira, de revelar algum aspecto espiritual.

Os dados corroboram ainda a noção de que espiritualidade é algo presente na vida e na prática profissional dos executivos entrevistados. Porém, na maioria das vezes, o tema é apresentado de forma inominada (sabe-se da presença de algo superior, porém, não se sabe nomear); por vezes escondido (no silêncio da experiência de cada um; pela falta de espaço para se manifestar); e até negligenciado (não se presta muita atenção a tais elementos, ainda que eles existam).

As entrevistas deixaram evidente que esses executivos têm um sentido de dever, de chamado, de fazer o bem, de servir e de cuidar do outro. Mais de um dos CEOs participantes se emocionou no decorrer das entrevistas presenciais. Aspectos espirituais estão presente nas ações destes indivíduos que, em boa parte do tempo, não se dão conta, de forma clara, que é disso que se trata. Em outras palavras, acreditam numa 'força maior', em 'algo superior', mas o emaranhado do cotidiano engole as oportunidades de tradução de tais experiências em uma vivência espiritual. 
Os executivos entrevistados certamente têm uma expertise para os negócios, para gerir empresas e projetos. Todos eles sêniores e referências de sucesso no mundo empresarial, aprenderam com a vida, com as crises, com uma capacidade intuitiva que lhes permite fazer escolhas, tomar decisões, errar e acertar. Ao lado dessas competências, é possível notar a presença de valores importantes, como fé ("e não religião"), coletividade, cuidado com o outro, atenção, respeito, humildade, revelando a dimensão espiritual desses homens e mulheres no cotidiano das organizações e no exercício de liderar. Tais atributos estão intimamente relacionados à noção de liderança servidora discutida na revisão teórica deste artigo.

Não ficou evidente, em boa parte das entrevistas, que exista uma clareza quanto ao lugar e a influência - de forma direta e explícita - da espiritualidade em sua vida e prática de liderança. Em outras palavras, com algumas exceções, houve certa dificuldade em explicitar que sua experiência executiva e de liderança carregam alguma espiritualidade. Talvez pelo fato de associarem, num primeiro momento, o espiritual com o religioso.

A espiritualidade, para alguns, vem caracterizada pela prática moral nas relações, no compromisso com a causa coletiva, no respeito ao ser humano, no cuidado com o outro. Outros manifestam ainda uma espiritualidade através da preocupação com o planeta, com a perpetuidade da empresa, em fornecer um legado positivo para a humanidade. Cabe aqui ressaltar que investigar a presença e a influência da ética, da moral e seus elementos em relação à espiritualidade é uma proposição para futuras pesquisas.

Fica a proposição de promover espaços e oportunidades para instigar a reflexão e o aprofundamento sobre a espiritualidade e suas dimensões, uma vez que elas estão presentes no cotidiano das organizações e das lideranças. Portanto, promover diálogos, cursos, seminários e retiros sobre o tema com a finalidade ajudar profissionais a tornarem o tema mais integrado e natural no mundo corporativo.

Quanto aos estudos futuros, muitos são os desafios que a conexão dos temas espiritualidade e liderança oferecem. Alguns deles foram tocados neste artigo, porém, merecendo maior aprofundamento como, por exemplo, o papel da intuição em relação a ambos os temas (espiritualidade e liderança); os tipos psicológicos e sua 
interferência tanto na espiritualidade como no exercício da liderança; outros estilos de liderança, além da servidora e sua interferência na percepção da espiritualidade; o papel da religiosidade como mecanismo de formação e conformação dos estilos de liderança e da espiritualidade.

\section{REFERÊNCIAS}

ARGANDOÑA, A. Beyond contracts: love in firms. Journal of Business Ethics, v. 99, n. 1, p. 77-85, 2011.

BARBUTO, J. E.; JR., WHEELER, D. W. Scale development and construct clarification of servant leadership. Group Organization Management, v. 31, n. 3, p. 300-326, 2006.

BARDIN, L. Análise de Conteúdo. São Paulo: Edições 70. Edição revista e ampliada, 2016.

BENEFIEL, M. (2008). The soul of a leader. Finding your path to success and fulfillment. New York: The Crossroad Publishing Co, 2008.

BOLMAN, L. G.; DEAL, T. E. Liderança com alma. Uma parábola sobre a busca da paixão e determinação no trabalho e na vida. Rio de Janeiro: Ediouro, 1996.

DAMIÃO, W. S.; OSWALDO, Y. C.; VIEIRA, A. M. Espiritualidade na Perspectiva de Trabalhadores e Futuros Trabalhadores: Análise dos Níveis de Domínio por Parte de Estudantes Amazonenses. Revista Eletrônica Gestão e Serviços, v. 11, n. 2, p. 3130-3149, 2020.

DAY, D.; FLEENOR, J. W.; ATWATER. L. E.; STURM, R. E.; MCKEE, R. A. Advances in leader and leadership development: a review of 25 years of research and theory. The Leadership Quarterly, v. 25, n. 2, p. 63-82, 2014.

DENT, E. B.; HIGGINS M. E.; WHARFF, D. M. Spirituality and leadership: an empirical review of definitions, distinctions and embedded assumptions. The Leadership Quarterly, v. 16, p. 625-653, 2005.

DUMAS, C.; BEINECKE, R. H. Change leadership in the $21^{\text {st }}$ century. Journal of Organizational Change. V. 31, n. 4, p; 867-876, 2018.

EISENHARDT, K. M.; GRAEBNER, M. E. Theory building from cases: opportunities and challenges. Academy of Management Journal, v. 50, n. 1, 25-32, 2007.

FERNANDES, C. M.; SIQUEIRA, M. M. M.; VIEIRA, A. M. Impacto da percepção de suporte organizacional sobre o comprometimento organizacional afetivo: o papel moderador da liderança. Revista Pensamento Contemporâneo em Administração, v. 8, n. 4, p. 140-162, 2014.

FRY, L. W.; ALTMAN, Y. Spiritual Leadership in action. The CEL story. Achieving extraordinary results through ordinary people. Charlotte (NC): IAP, Inc, 2013.

FRY, L. W.; SLOCUM Jr., J. W. Maximizing the triple bottom line through Spiritual Leadership. Organizational Dynamics, v. 37, n. 1, p. 86-96, 2007. 
FRY, L. W. Toward a theory of spiritual leadership. The Leadership Quarterly, v. 14, p. 693-727, 2003.

GANDOLFI, F.; STONE, S. The emergence of leadership styles: a clarified categorization. Review of International Comparative Management. v. 18, n. 1, p. 18-30, 2017.

GARCÍA. J. A. En el mundo desde Dios: Vida Religiosa y resistencia cultural. Santander: Sal Terrae, 1989.

GEHRKE, S, J. Leadership through Meaning-Making: an empirical exploration of spirituality and leadership in college students. Journal of College Students Development, v. 49, n. 4, p. 351-359, 2008.

GREENLEAF, R. Servant Leadership. A journey into the nature of legitimate power greatness. $25^{\text {th }}$. anniversary edition. New York/Mahwah, N.J.: Paulist Press, 2002.

HEYLER, S. G.; MARTIN, J.A. Servant Leadership theory. Opportunities for additional theoretical integration. Journal of Managerial Issues. v. 30, n. 2, p. 230-243, 2018.

HOLLOWAY, M. Spirituality. International Encyclopedia of the Social Behavioral Sciences, 2nd edition, v. 23, p. 285-289, 2015.

KARAKAS, F. Spirituality and Performance in Organizations: a literature review. Journal of Business Ethics, v. 94, p. 89-106, 2010.

KOK, J.; HEUVEL, S. V. Leading in a VUCA world. Integrating leadership, discernment and spirituality. Switzerland: Springer International Publishing. XVI, 2019.

KRISHNAKUMAR, S; HOUGHTON, J. D.; NECK, C. P.; ELLIS, ON, C. N. The "good" and the "bad" of Spiritual Leadership. Journal of Management, Spirituality Religion, v.12, n. 1, p. 17-37, 2015.

LEVY, R. My Experience as Participant in the Coursek on Spirituality for Executive Leadership. Journal of Management Inquiry, v. 9, n. 2, p. 129-131, 2000.

LIDEN, S. J.; WAYNE, J. D.; MEUSER; J. HU; J. WU; C. LIAO. (2015). “Servant Leadership: Validation of a Short Form of the SL-28." Leadership Quarterly, v. 26, n. 2, p. 254-269.

LOURENÇO, C. D. S.; FERREIRA; P. A. BRITO, M. J. O significado do trabalho para uma executiva: a dicotomia prazer e sofrimento. Organizações em Contexto, São Bernardo do Campo (SP), v. 9, n. 17, p. 247-279, 2013.

MACKENZIE, M. L.; SERVANT, G. The value of spirituality within the workplace: a discussion and proposal for research. Northeast Decision Sciences Institute Proceedings, p. 135-149, 2011.

MALVEZZI, S. A ação de liderança: uma tarefa de aprendizado contínuo. Nova Lima (MG), FDC, Revista DOM, v, 15, n. jul-out, p. 15-21, 2011.

MARQUES, R. Líderes Ubuntu a três tempos - cuidar, ligar e servir. In: Construir Pontes Ubuntu - Para uma liderança servidora. Academia de Líderes Ubuntu. Disponível em: https:// www.academialideresubuntu.org/pt/, 2018.

MARTINS, G. J. T.; PEREIRA, M. F. Contribuições da liderança espiritual para o desempenho organizacional sustentável. Revista de Administração FACES Journal, v. 8, n. 1, art. 31, p. 87-106, 2009. 
MENDES, L.; SANT'ANNA, A. S; DINIZ, D. M. Liderança e Modernidade Organizacional em Escritórios de Advocacia. In: VII Encontro de Gestão de Pessoas e Relações de Trabalho - EnGPR, 2020: ANPAD, 2020.

MESKELIS, S.; BELDONA, S.; WHITTINGTON, J. L. Exploring the spirituality-meaningfulness-engagement relationship: A cross-cultural analysis. Paper presented at the AIB 2016 Annual Meeting, New Orleans, Lousiana, USA, 2016.

MOLTMANN, J. O espírito da vida: Uma pneumatologia integral. 2ª . ed. Petrópolis: Vozes, 2010.

MOTA, C.M.; TANURE, B.; CARVALHO NETO, A. Estresse e sofrimento no trabalho dos executivos. Psicologia em Revista, Belo Horizonte, v. 14, n. 1, p. 107-130, 2008.

NULLENS, P. From Spirituality to Responsible Leadership: Ignatian Discernment and Theory-U. In: Leading in a VUCA world. Integrating leadership, discernment and spirituality. Switzerland: Springer International Publishing. XVI, 185-207, 2019.

OLIVEIRA, F. B.; SANT'ANNA, A. S.; DINIZ, D. M.; CARVALHO NETO, A. M. Leaderships in Urban Contexts of Diversity and Innovation: The Porto Maravilha Case. BAR - Brazilian Administration Review, v. 12, n. 3, p. 268-287, 2015.

PATTERSON, K. Servant Leadership, a theoretical model. School of leadership studies: Regent University, p. 1-10, 2003.

REAVE, L. Spiritual values and practices related to leadership effectiveness. The Leadership Quarterly, v. 16, n. 5, p. 655-687, 2005.

Sant'Anna, A. S.; Sorel C. M; Lótfi, S. (2012) Liderança: o que pensam executivos brasileiros sobre o tema? RAM. Revista de Administração Mackenzie, 13(6), nov/dez, 48-76.

SANT'ANNA, A. S.; NELSON, R. E. Leadership to new forms of leadership: movements and trends beyond mainstream. Reuna, v. 19, n. 4, 5-20, 2014.

SILVA, A. H.; FOSSÁ, M. I. T. Análise de Conteúdo: Exemplo de Aplicação da Técnica para Análise de Dados Qualitativos. IV Encontro de Ensino e Pesquisa em Administração e Contabilidade (EnEPQ). Brasília (DF), p. 1-14, 2013.

SOLOMON, R. C. (2003). Espiritualidade para céticos: Paixão, verdade cósmica e racionalidade no século XXI. Rio de Janeiro: Civilização Brasileira, 2003.

TANURE, B.; CARVALHO NETO, A.; ANDRADE, J. O. A super executiva às voltas com carreira, relógio biológico, maternidade, amores e preconceitos. ENANPAD. Salvador (BA), 2006.

TANURE, B.; MOTA, C.M.; CARVALHO NETO, A.; NUNES, S.C. O tipo psicológico dos altos executivos brasileiros e a percepção de estresse: onde os "fracos" não têm vez. BASE - Revista de Administração e Contabilidade da Unisinos, v. 12, n.1, p. 40-51, 2015.

TENFEN, M. F.; VENELLI-COSTA, L.; VIEIRA, A. M.; SANEMATSU, L. S. A. Espiritualidade no Ambiente de Trabalho e sua Relação com a Percepção de Sucesso na Carreira do Indivíduo. Contabilidade, Gestão e Governança, v. 22, n. 2, p. 153-170, 2019.

VAN DIERENDONCK, D. Servant Leadership: A Review and Synthesis. Journal of Management, v. 37, n. 4, p. 1228-1261, 2011. 
VAN DIERENDONCK, D.; STAM, D.; BOERSMA, P.; WINDT, N.; ALKEMA, J. Same difference? Exploring the differential mechanisms linking servant leadership and transformational leadership to follower outcomes. The Leadership Quarterly, v. 25, n. 3, p. 544-562, 2014.

VIEIRA, A. M.; RIVERA, D. P. B. A Hermenêutica no Campo Organizacional: duas possibilidades interpretativistas de pesquisa. Revista Brasileira de Gestão de Negócios, v. 14, n. 44, p. 261-273, 2012.

YIN, R. K. The Case Study Crisis: Some Answers. Administrative Science Quarterly, v. 26, n. 1, p. 58-65, 1981.

Recebido em: 5-3-2021

Aprovado em: 29-7-2021

Avaliado pelo sistema double blind review.

Disponível em http://mjs.metodista.br/index.php/roc 